\title{
Student's perspectives on enhancing research in ODL in selected higher learning institutions in Zambia
}

\author{
Rose Chikopela ${ }^{1}$, Daniel L. Mpolomoka ${ }^{2}$, Francis S. Sikanyika ${ }^{3}$, Grace Sondashi ${ }^{4}$, Cynthia N. Kalizinje ${ }^{5}$ and Judith \\ Zimba $^{6}$ \\ ${ }^{I}$ Zambia Institute of Special Education, Department of Hearing Impairment, Lusaka, Zambia. \\ ${ }^{2}$ ZambianOpen University, School of Education, Lusaka, Zambia. \\ ${ }^{3}$ Bwalya Mponda Secondary School, Department of Guidance and Counselling, Lunga, Zambia. \\ ${ }^{4}$ Libala Secondary School, Department of Guidance and Counselling, Lusaka, Zambia. \\ ${ }^{5}$ Royal Monze Institute of Medical Evangelism, Department of Philanthropy, Lusaka, Zambia. \\ ${ }^{6}$ Lundazi Day Secondary/DEBS Office, Department of Guidance and Counselling, Lundazi, Zambia.
}

Corresponding Author*

\begin{abstract}
The study was undertaken to analyze student's perspectives on enhancing research in Open and Distance Learning (ODL) in Lusaka. A descriptive survey design was used. The sample comprised 25 students in five institutions of learning in Lusaka who were purposively and randomly selected. Data was collected using questionnaires and semi-structured interview guides, while analysis of data was done using SPSS and themes. The study revealed that there are different student perspectives on enhancing research in ODL during COVID-19. There is a dire need to enhance research in ODL among students, and that students are positive about enhancing research in ODL. The study established that enhancing research in ODL can in turn improve the quality of ODL programmes and increase the student's research skills. The study also revealed that using different approaches or strategies and/or methods in research can enhance research in ODL during COVID-19. The study suggests that students should engage in many research endeavors in ODL, carryout research studies with experienced lecturers so that they can learn better, collaborate with other students pursing programmes via ODL platforms. This study concludes research in ODL is very vital in making ODL a worthwhile alternative to other forms of learning.
\end{abstract}

Keywords: COVID-19, Student, Perspective, Research, ODL.

\section{INTRODUCTION AND BACKGROUND}

$\mathrm{R}$ esearch is very vital in Open and Distance Learning (ODL). There have been changes in the provision of ODL programmes. One of these changes is research (Gaba, 2001).Therefore, there is a great deal of research in ODL just like in conventional education system (traditional education).

The genesis of distance education can be traced back to 1850 when Sir Isaac Pitman thought of a way of delivering instruction methods rather than a class arrangement of face to face (Curran, 1997). Since there has been tremendous growth enabling both developed and developing countries providing distance education across the globe.As a result, Distance Teaching Institutions (DTIs) have developed research policies and set up separate research departments. The first systematic research in ODL and/or distance education was initiated in late 1950's and published in 1959 by the East German scholar
J.R. Freiburg. Most of the research work came from a group from German Institute of Distance Education during the 1960’s and early 1970’s (Gaba, 2001).

There have been a lot of changes that have taken place in ODL research. Consequently, there has been an increased effort by ODL institutions to involve students in research activities. Students have undertaken research projects mainly concerned with issues that would improve the ODL system such as teaching and learning. For instance, Moore and Thompson (1997) focused more on topics such as Faculty Issues in ODL system. Similarly, more scholars identified new areas of research and general trends in distance education learning in general.

Notably, Open Universities in the modern sense have expanded with largest numbers been found in United States, Asia, Europe, Latin America, Australia including Africa(Talt, 2018). Masterman (2016) observes that Open Universities have adopted ODL systems with better diversity of education by initiating research-led, research-oriented and researchbased curriculums. These curriculums involve research activities in the learning process which focuses on writing and discussing papers or essays thereby enhancing research skills. In addition Passi (2004) revealed that ODL system is using networking to disseminate research outcome through presentation at conferences, meetings, fora, other gathering, publications and website dissemination, this gives recognition and motivation to researches and institutions. This entails that students have been given the ability to investigate a problem, make judgment on the basis of sound evidence, take decisions on the rational basis and understand what they are doing (Healey, Jenkins and John, 2014). For example, the University of Zambia under Open and Distance Learning has adopted a project-based learning approach where the students are required to take a module courses for two semesters of their two year Master's Study and then final year focus on research-based project (University of Zambia, 2015). In addition, for Doctor of Philosophy (PhD) programmes it is not unusual to witness student's undertaking study by research 
courses the whole period of study whilst involved in academic activities such as tutoring/lecturing.

Many ODL institutions have recently created strong and imaginative policies for teaching and to an extent of research, thus allowing, both staff and students to conduct research projects. Distance teaching institutions have created an environment in which academicians are supported in research. In India for instance, the Distance Education Council is on the record of providing funding in form of grants for research studies to students undertaking distance education (Gaba, 2007). The purpose of this is to promote research work, enrich the quality and quantity of education and meet the challenges faced by various students.

In Zambia, the Education Policy supports and promotes the expansion of higher learning education and also pays special attention to open distance education. Large number of studies reveals that beginning of open distance education in Zambia is traced back to when the policy provided expansion to teacher training including in-service teachers who hoped to upgrade their qualifications. According to Siaciwena and Lubinda (2004) since 1964 open and distance learning has been used to increase access to and improve the quality of education. It is a requirement for Zambian ODL institutions to play a pivotal role in knowledge production so as to transform Zambian education and also in national development. To those who are enrolled in ODL institutions they follow a universally acceptable formal process to solve research problems. Supervisory guidance is provided to students in order to produce quality work. Therefore, the rising demand of open and distance learning has witnessed the opening of various Universities in the country; notable state owned and private offering open and distance education includes the University of Zambia, the Copperbelt University, Mulungushi University, Zambian Open University, University of Lusaka, Kwame-Nkurumah University, Africa Research University, Mufulira College of Education, among others.

Zambia differs in the area of research in ODL like other parts of the world (Tate, 1990). Each University has criteria in the provision of education, For example, a student may opt for a Master's by research or by course work. But usually in the Zambian system, Masters by research is common in conventional universities, whereas in open distance education it's a combination of course work and research in the final year of study, although with $\mathrm{PhD}$ students maybe be a different case. The quality of research output in the country is questionable; hence, it has been argued by Masaiti and Shen (2013) that failure to establish organized research faculties in the provision of distance education will be built on weak grounds. Some notable weakness have been analyzed, as such the collaborative efforts with Universities of high ranking is not taken seriously, therefore, Zambian researchers are not affiliated to recognized research bodies. The low levels of investment in ODL research system have denied Zambian researchers a chance to have improved ranking, international research collaborations and world share of knowledge. There is lack of proper documentation of postgraduates and doctorate, and because of this the country has a low international ranking. When compared to other African countries such as South Africa, Tunisia and Egypt, funding for ODL students is very low; actually it is as good nothing. The quality of a research environment is compromised, postgraduate and post-doctorate researchers lack national collaboration, making less progress in the research field. These factors also undermined the quality of education provided under education. Although its development is constrained by variety of factors, in general the design of distance education programmes which does not sufficiently support research and researchers still has room for improvement in the management of research. There is also need to have an educational policy that supports open universities in the whole country.

Naville (2007) describes research as "a process of enquiry and investigation; it is systematic, methodical and ethical; research can help solve practical problems and increase knowledge." In addition, Kapur (2012) explains that research is an imperative area in not just the field of education but in other fields as well, for instance it provides the basis for nearly all government policies in any economic system. There are various types of researches that are undertaken in ODL just like in convectional educational systems. These include fundamental or basic research and applied or action research.

Research in academics represents an activity, directed towards the development of an organized body of scientific knowledge about the events with which researchers are concerned. In ODL, students are often involved in different research activities. The significance of research in ODL cannot be overemphasized, as is an imperative area that enables scholars to acquire more knowledge on different subjects or areas which enables them to find solutions to identified problems. In addition, enhanced research further improves the quality of work of scholars and institutions, and brings about academic excellence. Various scholars use different tools for conducting research activities due to the fact that there are various research types. As a result of this, lecturers and regular researchers in various institutions of higher learning have different perspectives with regards to enhancing research in ODL. However, what is not known is student's perspectives on enhancing research in ODL, hence this study.

\section{Objectives of the Study}

1. To analyse student's perspective on enhancing research in ODL.

2. To ascertain research approaches, methods and/or tools that can best enhance research in ODL.

\section{THEORETICAL FRAMEWORK}

Distance education is not carried out haphazardly but falls within structures of a given operational mode. Marshall (2000:3) admits that educational theories tend to reflect the social, political, economic and philosophical values of a given 
period and related events. His view implies that theories are a product of existing circumstances and are, thus, formulated and implemented in order to address existing situations. Therefore, theories too guide the practice and research of distance education. Theories can be described from efforts to explain or make sense of observed phenomena, or by reasoning through the implications of existing theories. Theories are necessary because they help us to understand, communicate and predict the nature of a discipline or a field of practice, its purpose, goals, and methods. Indeed, theories help to shape practice, and practice in turn contributes to the development of theory.

However, this study is guided by Moore's (1991) theory of autonomy and independence. This theory is specifically directed at managing distance education. According to Bourchard and Kalman (1998) student autonomy is seen as a requisite in highly structured situations, where the student must compensate for the lack of pedagogical flexibility. Simultaneously, student autonomy is seen as indispensable when the student must deal with a lack of structure. According to Keegan (1986), contributions to theories of autonomy and independence were made in the late 1960s and early 1970s. The major representatives were Rudolf Manfred Delling (Federal Republic of Germany), Charles A. Wedemeyer (U.S.A.) and Michael G. Moore (U.K.). Delling (1978) (in Chifwepa 2006:23). ODL being as a multi-dimensional system of learning and communication processes with the aid of an artificial signal-carrier which has to facilitate learning. A signal carrier is a device which facilities learning. The eight dimensions of distance education that Delling identified are: a student, society, distance teaching institution, a learning objective, the content to be learned, the result of learning, distance, and a signal-carrier. The latter implies that there are support services that assist a student to learn. These are considered to be important in the provision of distance teacher education. In the theory of autonomy and independence, Moore (1991) recognizes the importance of the student's determination of his or her own learning pace and time. Nevertheless, within the framework of this independence is the need for effective dialogue between the lecturer and the student. This freedom of ODL should be considered when designing study materials. Indeed, distance education practitioners should devise systems that support this freedom. This can be in form of allowing students to exercise maximum independence with regard to choose of aims, objectives, study methods and learning activities, study pace and progression, and evaluation (Chifwepa 2006). The content to be learned, the result of learning, distance, and a signal-carrier which plays an important role in the theory of autonomy and independence are important in the provision of distance teacher education. Therefore, this theory guides the study by articulating issues related to distance students. The theory of autonomy and independence reduces the role of the teacher and that of the educational organisation to a minimum and places the entire emphasis on the autonomy and independence of the student.
The main aim of the theory of autonomy and independence is to develop in the student the capacity to carry out self-directed learning that will enable him or her to continue learning in his or her own environment (Moore 1991). This is very important especially in the area of research. Moore (2006) provides the following examples concerning the hypothesised relationship of autonomy, structure and dialogue: when autonomy is low the need for structure is high and when structure is low the need for autonomy is high; programmes with low dialogue require a high degree of student autonomy, and programmes with low dialogue as well as low structure also require a high degree of student autonomy. Students with high autonomy require less dialogue and less structure; highly autonomous students may engage in auto-dialogue, that is, a situation in which a student involves herself or himself in discussion about her or his studies; Course designers can develop highly structured courses with little room for student autonomy in setting goals, execution or evaluation, or can develop very unstructured courses, allowing students to exercise a high degree of autonomy; an autonomous student could put together a highly structured learning programme for him or herself or could develop a loosely structured programme. Using the examples above, ODL practitioners can design teacher education courses or materials for different degrees of student autonomy by varying dialogue and structure.

\section{METHODOLOGY}

\section{Research design}

Both qualitative and quantitative data was collected hence a descriptive survey design was used.

\section{Population, Sample and Sampling techniques}

A total of 25 participants were involved in the study, among which 15 were ODL students pursing studies by research while 10 were ordinary ODL students.Both probability (simple random) and non-probability (purposive) were used in the study to select ordinary ODL students and ODL Students pursuing studies by research respectively.

\section{Data Collection Instruments}

Interview guides were used to collect qualitative data while questionnaire were used to gather quantitative data respectively.

\section{Data Analysis}

Thematic analysis and SPSS (to obtain descriptive statistics) were used to analyze data qualitative and quantitative data respectively.

\section{FINDINGS}

\section{Students' perspective on enhancing research in $O D L$}

To analyze student's perspective on enhancing research in ODL participants were asked if they had more time to conduct research in ODL; whether there was a need to enhance research in ODL; if students pursuing ODL programmes were 
capable to undertake research on their own, and what research approaches, methods and/or tools that can best enhance research in ODL.

Figure1: Time to Conduct Research

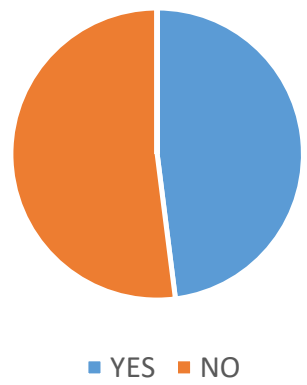

As to whether students had time to conduct research in ODL 12 respondents indicated yes whereas 13 indicated no representing $48 \%$ and $52 \%$ respectively as shown in the figure above.

Figure 2: Necessity of enhancing research in ODL

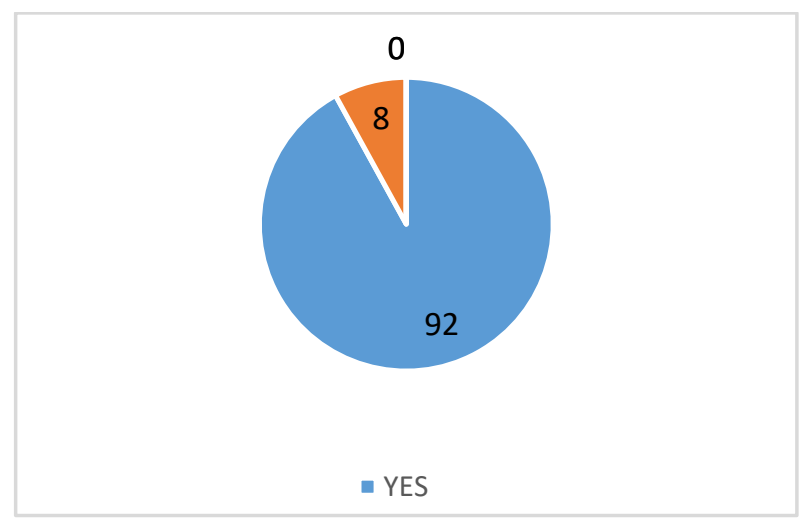

On the need to enhance research in ODL responses were that $23(92 \%)$ indicated Yes and $2(8 \%)$ indicated No. As shown in Figure 2 above.

Figure 3: Students Capability of Conducting Research

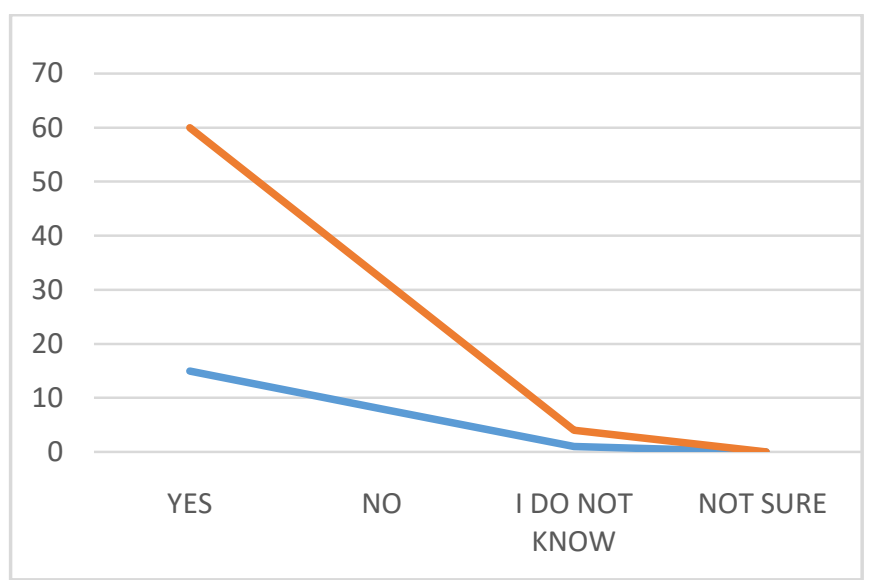

On student's capability on conducting personal research participant's opinion was sought on whether students pursuing ODL programmes were capable to undertake research on their own. $15(60 \%)$ indicated YES, 8 (32\%) indicated NO, 1 (4\%) indicated I DO NOT KNOW and no respondent indicated NOT SURE.

Research approaches, method or tools to enhance research in $O D L$

Participants were also asked what research approaches, methods or tools can be best used to enhance research in ODL; how can higher learning institutions enhance research in learning institutions and to give their perspective on enchaining research in ODL in higher learning institutions.

Participants provided various responses on the best approaches, methods and tools for example; S1, S2 and S8 provided that qualitative research approach was more convenient for students conducting research under distance learning, S23 stated that it depends on which approach the student find convenient. S10, S14, S11, S17 and S20 were of the view that both qualitative and quantitative research approaches were convenient for students conducting research under ODL. S4 also indicated 'that methods and tools were best defined by the study approach used in a study'.

However, on how learning institutions can enhance research in ODL S5, S7 and S10 indicated that the institutions can provide online library facility at a subsided rate as students pay highly on tuition fees and addition internet costs. S3 also provided a similar view that reduction of user fees would be a sure way of providing accessibility in terms of having the much-needed resources for research. S6 revealed as follows:

Distance education in itself encourages research as the student dedicates more time in the field making consultations due to limited contact with lecturers. A researcher also spends most of the time reading books which adds to the inquiry skill as the researcher gains more knowledge and desire to read further. Additionally, most institutions should adopt the provision of education through distance learning as otherstudents are fast in capturing knowledge through research as opposed to learning in the traditional classroom environment.

\section{DISCUSSION}

Students' perspective on enhancing research in $O D L$

The study revealed that there is need to enhance research in ODL. This is so because it was established that majority of respondents hadchallenges in findingtime to conduct research as opposed to those who had time. This could be attributed to failure or difficulties in balancing between family life, work and research. It can be stated that the $48 \%$ representation of those that had time for research is a significant number which points to that fact that enhancing research in ODL is indeed a sure way of reducing the gap between those that had 
challenges in finding time for research and those that never had any challenges.

In addition, the study shows that majority of respondents were in support of the need to enhance research in ODL. On the other hand, the study also shows that minority viewmaintained that 'there was no need to enhance research in ODL.' It can be argued that these respondents would be representing the section of respondents that are advantaged with regards to time, location and resource. Meaning the majority view is reflective of the very fact that most distance researchers are disadvantaged in a number of ways and therefore the need to enhance research in ODL will help narrow these disparities that exist in terms of accessibility of research materials, facilities and resources. These findings are certainly pointing to the need for the theory of equivalency used in the study which entails that the value of educational output in distance education and conventional learning should be the same. Similarly, students pursuing distance education regardless of location, time, race, gender and financial status should be provided with opportunities that enables them have the same chance to conduct quality research.

The study also revealed that majority of students pursuing distance programmes had the capacity to conduct research. However, $32 \%$ representation of those that gave a view that distance students are not able to conduct research leaves so much to be desired. This is so because of the possibility of students not conducting their own research and this brings the question on the caliber of students enrolled and quality of graduates under ODL programmes. Far more important than income generation in the universities is for higher learning institutions to produce a human resource that is able to produce maximum results.

Research approaches, method or tools to enhance research in $O D L$

The study established that both qualitative and quantitative research approaches were convenient for students conducting research under distance education.as these approachesact as a guide on therelevant research tools and methods for a particular study. The findings of the current study, are in line with Kobler and Bunker (1997) who argue that basic and applied research can be quantitative or qualitative or both. Mrozowski 2001 also maintained that ODL researchers use a variety of techniques both quantitative and qualitative as both have significant contributions in research. Study findings by Passi (2004) are that the most convenient for distant researchers is the use of quantitative research approach which present a contrast with the findings of the current study.

Study findings also revealed that the provision of library facility at a minimum or subsided rate and reduction of user fees are some ways in which the institutions of learning can enhance research among distance students. This points to the fact that when user fees are reduced it helps the researcher to have enough finances to carter for additional internet costs hence making it easy to access research materials or resources using internet sources. Consequently, an accessible library facility makes research work easy especially for students who are limited with internet access due to their geographical locations. This is in agreement with Masaiti and Shen who argues the quality of research output in the country is questionable due to failure in the provision of research facilities among distant researchers as discussed further in literature review.

In addition, findings also revealed that research in distance education is highly dependent on the level of interaction maintained by the researcher for example S6 arguedthat; "distance education in itself encourages research as the student dedicates more time in the field making consultations due to limited contact with lecturers. These consultations are a form of interactions which are always part of the distance education learning programme. These findings are in agreement with the theory of interaction used in the study as emphasis of the theory stresses of how interaction with the lecturer however little, students through group discussions and interaction with course modules and study materials are important is assuring successful completion of research in distance education.

The study further revealed that provision of programmes under distance learning encourages research and enhances the quality of research in students as opposed to the students under conventional or traditional classroom learning. The study also shows that distant education helps students to conduct more research which encourages autonomy on the part of the researcher, a principle that is highly utilized throughout the distant learning experience. Unlike the mentality where students have been conditioned to think that learning or research is only successful in a classroom or after a classroom experience in conventional learning. As most conventional universities encourage course work which is later supplemented by research work in the fourth or final year of the study as indicated in literature review earlier. The findings are in agreement with the theory of autonomy and independence used in the study.

Study findings by Gaba(2001) as alluded to earlier indicate that there is a great deal of research in distance education just like in conventional education system (tradition). These findings disagree with the findings in the current study which indicate that more research is done under distance learning as compared to conventional or face to face learning. As a student focuses on memorizing content in conventional learning as opposed to knowing and mastery of content in distant learning. Hence the need to enhance research facilities among distance researchers because the life of a distant student is solely dependent on research.

\section{CONCLUSION}

This study concludes research in ODL is very vital in making ODL a worthwhile alternative to other forms of learning. There are various approaches of enhancing research in ODL. 
In addition, students have positive perspectives on enhancing research in ODL.

\section{RECOMMENDATIONS}

1. Students should engage in many research endeavors in ODL.

2. Students should endeavor to carryout research studies with experienced lecturers so that they can learn better.

3. Students must collaborate with other students pursing programmes via ODL platforms.

4. Learning institution must have student deliberate programmes and policies aimed at enhancing research in ODL.

5. Students must have inspiring perspective on enhancing research in ODL.

\section{REFERENCES}

[1] Creswell, J.W. (2007). Qualitative Inquiry and Research Design. Thousand Oaks: Sage

[2] Publications

[3] Berge, Z.L. and Mrozowski, S. (2001). Review of Research in Distance Education, 1990 to 1999. The American Journal of Distance Education, 15(3), 5 - 19

[4] Dell, S. (2018, October, 2) South Africa 'Punches Above its Weight in Research, Says study. Johannesburg

[5] European Distance and E-Learning (2014). Challenges for Research into Open and Distance Learning. Oxford: The Open University

[6] Gaba, A. (2007). Research in Open and Distance Education: Status and Policy Issues. Indira Gandhi National Open University (IGNOU)

[7] Horta, H. (2008). On Improving the University Research Base. The Technical University of Lisbon Case in Perspective. Lisbon: University of Lesbon
[8] Healey, M., Jenkins, A.and Lea, J. (2014). Developing Research Based Curriculum in College Based Higher Education. The higher education academy

[9] Huenneke, L., Laurila, K.A., Martinez, J.M. and Sterns, D.M. (2017). Key Strategies for Building Research Capacity of University Faculty Members

[10] Kapur, R. (2012).Significance of Research in Education, India

[11] Kobler, M.A. and Bunker, E.L. (1997).Trends in Research and Practice: An Examination of the American Journal of Distance Education:The American Journal of Distance Education, 11(2): $19-38$

[12] Masterman, E. (2016). Bringing Open Education Practice to a Research - Intensive University: Prospects and Challenges. Oxford: University of Oxford

[13] Masaiti, G.and Sheng, H. (2013). Cost Sharing in Zambia's Public Universities: Prospects and Challenges. Wuhan: Huazhong University of Science and Technology

[14] Moore, M.G. and Thompson, M.M. (1997). The Effects of Distance Learning, rev.ed. ASCDE Research Monograph No.15, University Park, PA: the Pennsylvania State University.

[15] Naville Collin (2007). Effective Learning Service: Introduction to Research and Research Methods. Bradford: Bradford University School of Management.

[16] Nhlanhla, B.W.M. (2016). Enhancing Research Culture and Experiences of Academic staff and $P G$ Students in a Comprehensive University Environment- A case of the University Zululand. KwaZulu- Natal: University of Zululand.

[17] Passi, B.K.(2004). Selecting Research Areas and Research Design Approaches in Distance Education: Process issues. Sudarshan Mishra: University of Technology

[18] Ranjit, K. (2005). Research methodology-a-step-by-step guide for beginners, 2nd.ed, Singapore: Pearson Education

[19] Siaciwena, R. andLubinda, F. (2014). The Role of Open and Distance Education in the Implementation of the Rights to Education in Zambia. Athabasca: Athabasca University.

[20] Talt, A. (2018). Open Universities: The Next Phase. Milton Kaynes: The Open University.

[21] Tate, O. (1990).Distance education in Zambia. Vancouver: Commonwealth of Learning. 